Article

\title{
Optimization of Ultrasonic Extraction of Phenolic Antioxidants from Green Tea Using Response Surface Methodology
}

\section{Lan-Sook Lee, Namhyouck Lee, Young Ho Kim, Chang-Ho Lee, Sang Pil Hong, Yeo-Won Jeon and Young-Eon Kim *}

Korea Food Research Institute, Seongnam, Kyonggi 463-746, Korea;

E-Mails: sohee0809@hanmail.net (L.-S.L.); Inh@kfri.re.kr (N.L.); youngho@kfri.re.kr (Y.H.K.); chang@kfri.re.kr (C.-H.L.); sphong@kfri.re.kr (S.P.H.); 02callalily@ naver.com (Y.-W.J.)

* Author to whom correspondence should be addressed; E-Mail: radog@kfri.re.kr;

Tel.: +82-31-780-9072; Fax: +82-31-709-9876.

Received: 24 September 2013; in revised form: 21 October 2013 / Accepted: 26 October 2013 / Published: 31 October 2013

\begin{abstract}
Response surface methodology (RSM) has been used to optimize the extraction conditions of antioxidants with relatively low caffeine content from green tea by using ultrasonic extraction. The predicted optimal conditions for the highest antioxidant activity and minimum caffeine level were found at 19.7\% ethanol, 26.4 min extraction time, and $24.0{ }^{\circ} \mathrm{C}$ extraction temperature. In the predicted optimal conditions, the experimental values were very close to the predicted values. Moreover, the ratio of $(\mathrm{EGCg}+\mathrm{ECg}) / \mathrm{EGC}$ was identified a major factor contributing to the antioxidant activity of green tea extracts. In this study, ultrasonic extraction showed that the ethanol concentration and extraction time used for antioxidant extraction could be remarkably reduced without a decrease in antioxidant activity compared to the conventional extraction conditions.
\end{abstract}

Keywords: green tea; caffeine; antioxidant; ultrasonic extraction; response surface methodology

\section{Introduction}

Tea is the most widely consumed beverage in the World next to water and is known for its various health benefits [1,2]. Polyphenolic compounds, a complex group of secondary metabolite substances found in plants, act as antioxidants, UV protectants, antimutagenic, anticarcinogenic, and 
antimicrobial agents. Green tea contains various classes of polyphenols, and up to $90 \%$ of its polyphenols is composed of flavan-3-ols (tea catechins). (+)-Catechin (C), (-)-epicatechin (EC), $(+)$-gallocatechin (GC), (-)-epigallocatechin (EGC), (-)-epicatechin gallate (ECg), (-)-epigallocatechin gallate (EGCg), and (+)-gallocatechin gallate $(\mathrm{GCg})$ are the major catechins found in green tea leaves [3]. Among these catechins, EGCg is well known as a strong antioxidant. Green tea extracts have been used in functional food products to enhance the health benefits and to increase the shelf life because of their high antioxidant activity. For example, the tea catechins have been added to cereals, cakes, biscuits, ice cream, instant noodles, fried snacks, sausages, and soft drinks [4,5]. Conversely, the caffeine component of green tea has both positive and negative effects on health. It is a central nervous system and metabolic stimulant, and reduces physical fatigue and drowsiness at low doses. However, at high doses (typically greater than $300 \mathrm{mg}$ ), caffeine stimulates the cerebral cortex to induce excitation in the central nervous system, and also causes irritation of the gastrointestinal tract and sleeplessness for certain people [6,7]. Thus, it is necessary to reduce the contents of caffeine in green tea extracts to realize its optimum health benefits.

In order to extract the green tea, hot water and organic solvent extraction are the most commonly used procedures [8-12]. In general, the yield of solvent extraction depends on the type of solvents, with varying polarities, extraction time, and temperature, as well as on the physicochemical properties of the samples. Therefore, there is no single step procedure that can extract all phenolic compounds. Solvent extracts may also contain some non-phenolic compounds, including caffeine. As a result, reduction of caffeine may be necessary in order to avoid criticism of green tea extracts as promoting over-consumption of caffeine. Additionally, long extraction times and high temperatures cause the degradation and epimerization of catechins which reduces the antioxidant activity of green tea extracts $[13,14]$. The conventional extraction methods, such as shaking and solvent extraction, have shown low efficiency and potential environmental pollution due to the large volumes of organic solvents used, as well as long extraction time and high temperature required in those methods. At present, there is interest in developing a new extraction method based on the use of environmentally friendly processes offering short extraction times, low temperatures, and small amounts of organic solvents. Supercritical fluid, microwave, and ultrasonic extraction methods are emerging as good alternatives to conventional extraction methods, mainly due to lack of need for organic solvents and relatively short extraction times [15-18]. However, the supercritical fluid extraction method has some defects such as longer extraction time and high extraction pressure, resulting in high operating costs and limiting its large-scale industrial application. The microwave extraction method removes other taste- and aroma-causing compounds from tea. One the other hand, ultrasonic extraction has been widely used in the extraction of various phenolic compounds due to the relatively low cost and simple instruments needed [19-22]. In this study, ultrasonic extraction was used to extract the green tea extracts.

Response Surface Methodology (RSM) has been widely used for the optimization of extraction conditions such as temperature, extraction time and concentration of solvents. RSM consists of mathematical and statistical techniques used to develop an adequate functional relationship between a response of interest and some independent variable.

The aim of this study was to optimize, using RSM, the ultrasonic extraction conditions for antioxidants with relatively low caffeine content from green tea. Additionally, the most important factors contributing to the antioxidant activity of green tea extracts were determined. 


\section{Results and Discussion}

\subsection{Fitting the Models}

An optimization of extraction conditions for the extraction of antioxidants with relatively low caffeine content from green tea was conducted using RSM. The extraction efficiency of antioxidant compounds was influenced by extraction conditions including extraction solvent properties, extraction time, and extraction temperature [23,24]. RSM is accepted as a powerful tool in optimizing experimental conditions to maximize various responses [25-28].

For RSM, the levels of independent variables for the extraction of the antioxidant catechins were selected based on the results obtained from our preliminary experiments. The experimental design and corresponding response data are presented in Table 1 . Twenty experiments were designated and six were zero point tests performed to estimate the errors. The ranges of ethanol concentration $(19.7 \%-80.3 \%)$, extraction time $(26.4-93.6 \mathrm{~min})$, and extraction temperature $\left(14.8-65.2{ }^{\circ} \mathrm{C}\right)$ were used. Antioxidant activity and caffeine were used as responses in the RSM experimental design. Predicted response $\mathrm{Y}$ for extraction of the antioxidant green tea extracts could be obtained by applying multiple regression analysis on the experimental data. The predicted quadratic polynomial models are shown in Table 2. The models were checked using a numerical method including the coefficient of determination $\left(\mathrm{R}^{2}\right)$. $\mathrm{R}^{2}$ provided a measure of how well future outcomes are likely to be predicted by the model. In the models, $\mathrm{X}_{1}{ }^{2}, \mathrm{X}_{2}{ }^{2}$, and $\mathrm{X}_{1} \mathrm{X}_{2}$ were associated with synergistic effects on the antioxidant activity whereas $X_{1}$ and $X_{2}$ were associated with antagonistic effects. In addition, $X_{1}$ and $X_{3}^{2}$ were associated with synergistic effects on the caffeine whereas $\mathrm{X}_{1}^{2}, \mathrm{X}_{2}^{2}$, and $\mathrm{X}_{1} \mathrm{X}_{3}$ were associated with antagonistic effects. The $\mathrm{R}^{2}$ of the models for antioxidant activity and caffeine was 0.8961 and 0.9101 , respectively. Moreover, the coefficient of variation (CV) was 2.27 and 3.68, respectively, which indicates that a relatively lower value of $\mathrm{CV}$ showed a better reliability of the response model.

In general, lack of fit test for the model describes the variation in the data around the fitted model [29]. If the model does not fit the data well, the value of lack of fit will be significant and then proceeding with investigation and optimization of the fitted response surface is likely to give misleading results. Table 3 shows the analysis of variance of the fitted quadratic polynomial model for antioxidant activity and caffeine. For antioxidant activity, the linear parameters $\left(\mathrm{X}_{1}, \mathrm{X}_{2}\right)$ and interaction parameters $\left(\mathrm{X}_{1} \mathrm{X}_{2}, \mathrm{X}_{1} \mathrm{X}_{3}\right)$ were significant at the level of $p<0.01$ and quadratic parameter $\mathrm{X}_{1}^{2}$ was significant at the level of $p<0.05$. In the caffeine, $\mathrm{X}_{1}$ and $\mathrm{X}_{1} \mathrm{X}_{2}$ were significant at the level of $p<0.001$ and $\mathrm{X}_{2} \mathrm{X}_{3}$ was significant at the level of $p<0.05$. Moreover, the models used to fit response variable were significant $(p<0.01)$ and the lack of fit was not significant $(p>0.05)$ for all responses. It is indicated that the models used to fit responses variable were adequate to represent the relationship between the response values and the independent variables.

\subsection{Response Surface Optimization of Ultrasonic Extraction}

To visualize the relationship between the response and experimental levels of the independent variables for the antioxidants extraction, three-dimensional (3D) surface plots were constructed according to the quadratic polynomial model equations of Table 2. 
Table 1. Coded and processed variables levels used in experimental design for RSM.

\begin{tabular}{cccccc}
\hline & \multicolumn{3}{c}{ Coded and Processed Variable Level } & \multicolumn{2}{c}{ Response (mg/g) } \\
\cline { 2 - 6 } Run No. & $\mathbf{X}_{\mathbf{1}}$ & $\mathbf{X}_{\mathbf{2}}$ & $\mathbf{X}_{\mathbf{3}}$ & $\mathbf{Y}_{\mathbf{1}}$ & $\mathbf{Y}_{\mathbf{2}}$ \\
\cline { 2 - 6 } & $\mathbf{E t h a n o l ~ c o n c e n t r a t i o n ~}$ & $\begin{array}{c}\text { Extraction time } \\
(\boldsymbol{\%})\end{array}$ & $\mathbf{E x t r a c t i o n ~ t e m p e r a t u r e ~}$ & $\begin{array}{c}\text { Antioxidant activity } \\
\mathbf{( \% )}\end{array}$ & $\begin{array}{c}\text { Caffeine content } \\
(\mathbf{m g} / \mathbf{g})\end{array}$ \\
\hline 1 & $0(50)$ & $0(60)$ & $1.682(65.2)$ & 80.48 & 19.49 \\
2 & $0(50)$ & $0(60)$ & $0(40)$ & 79.77 & 18.54 \\
3 & $-1(32)$ & $-1(40)$ & $-1(25)$ & 79.43 & 16.84 \\
4 & $1(68)$ & $-1(40)$ & $1(55)$ & 80.22 & 18.08 \\
5 & $0(50)$ & $0(60)$ & $0(40)$ & 79.58 & 17.96 \\
6 & $0(50)$ & $0(60)$ & $0(40)$ & 79.51 & 18.22 \\
7 & $0(50)$ & $-1.682(26.4)$ & $0(40)$ & 79.49 & 17.93 \\
8 & $0(50)$ & $0(60)$ & $0(40)$ & 79.09 & 18.07 \\
9 & $-1(32)$ & $1(80)$ & $-1(25)$ & 79.62 & 17.31 \\
10 & $1(68)$ & $-1(40)$ & $-1(25)$ & 79.62 & 18.04 \\
11 & $0(50)$ & $0(60)$ & $0(40)$ & 78.87 & 18.00 \\
12 & $-1.682(19.7)$ & $0(60)$ & $0(40)$ & 79.67 & 16.39 \\
13 & $1(68)$ & $1(80)$ & $-1(25)$ & 82.99 & 18.33 \\
14 & $0(50)$ & $0(60)$ & $0(40)$ & 77.28 & 18.56 \\
15 & $0(50)$ & $0(60)$ & $-1.682(14.8)$ & 77.07 & 18.08 \\
16 & $0(50)$ & $1.682(93.6)$ & $0(40)$ & 82.36 & 18.04 \\
17 & $1.682(80.3)$ & $0(60)$ & $0(40)$ & 83.78 & 18.01 \\
18 & $-1(32)$ & $-1(40)$ & $1(55)$ & 80.84 & 17.33 \\
19 & $1(68)$ & $1(80)$ & $1(55)$ & 83.6 & 18.67 \\
20 & $-1(32)$ & $1(80)$ & $1(55)$ & 81.45 & 18.09 \\
\hline & & & & &
\end{tabular}

Table 2. Coded and processed variables levels used in experimental design for RSM.

\begin{tabular}{clcc}
\hline Responses & \multicolumn{1}{c}{ Quadratic polynomial model equations } & $\mathbf{R}^{\mathbf{2}}$ & $\mathbf{C V}(\%)$ \\
\hline \multirow{2}{*}{ Antioxidant activity } & $91.5074 * * *-0.3590 \mathrm{X}_{1} * *-0.2940 \mathrm{X}_{2} * *+0.0857 \mathrm{X}_{3}+0.0032 \mathrm{X}_{1}^{2} * *$ & & \\
& $+0.0019 \mathrm{X}_{2}^{2} * *+0.0000 \mathrm{X}_{3}^{2}+0.0021 \mathrm{X}_{1} \mathrm{X}_{2} *-0.0009 \mathrm{X}_{1} \mathrm{X}_{3}+0.0002 \mathrm{X}_{2} \mathrm{X}_{3}$ & 0.8961 & 2.27 \\
Caffeine & $12.1785 * * *+0.1707 \mathrm{X}_{1} * * *+0.0394 \mathrm{X}_{2}-0.0341 \mathrm{X}_{3}-0.0012 \mathrm{X}_{1}{ }^{2} * * *$ & & \\
content & $-0.0003 \mathrm{X}_{2}{ }^{2}+0.0007 \mathrm{X}_{3}^{2} *-0.0001 \mathrm{X}_{1} \mathrm{X}_{2}-0.0004 \mathrm{X}_{1} \mathrm{X}_{3} *+0.0002 \mathrm{X}_{2} \mathrm{X}_{3}$ & 0.9101 & 3.68 \\
\hline
\end{tabular}

$\mathrm{CV}$, coefficient of variation; $\mathrm{X}_{1}$, ethanol concentration; $\mathrm{X}_{2}$, extraction time; $\mathrm{X}_{3}$, extraction temperature.

$*$ Significant at $p<0.05 ; * *$ Significant at $p<0.01$; *** Significant at $p<0.001$.

The effect of the variables and their interaction on the responses can be seen Figures 1 and 2. As shown in Figure 1A, when extraction temperature was fixed at 0 level, antioxidant activity was increased slightly by increasing ethanol concentration from $37 \%$ to $80.3 \%$ and reached the maximum value at the highest ethanol concentration in the fixed extraction time of $60 \mathrm{~min}$. Figure $1 \mathrm{~B}$ shows the effect of the interaction of ethanol concentration and extraction temperature on the antioxidant activity at a fixed extraction time of 0 level. Maximum antioxidant activity was obtained at the lowest ethanol concentration and then decreased slightly by increasing ethanol concentration to $60 \%$ in the fixed extraction temperature of $40{ }^{\circ} \mathrm{C}$. Figure $1 \mathrm{C}$ shows the effect of the interaction of extraction time and extraction temperature on the antioxidant activity at a fixed ethanol concentration of 0 level. Maximum 
antioxidant activity was obtained at the lowest extraction time and then decreased slightly by increasing extraction time in the fixed extraction temperature of $40{ }^{\circ} \mathrm{C}$.

Table 3. Analysis of variance results for the regression equation.

\begin{tabular}{cccccc}
\hline Source & Degree of freedom & Sum of squares & Mean square & $\boldsymbol{f}$-value & $\boldsymbol{p}$-value \\
\hline Antioxidant activity & & & & & \\
\hline Model & 9 & 56.6980 & 5.9372 & 9.59 & 0.001 \\
$\mathrm{X}_{1}($ Ethanol\%, v/v) & 1 & 10.5842 & 9.8906 & 15.05 & 0.003 \\
$\mathrm{X}_{2}($ Time, min) & 1 & 11.2031 & 7.7975 & 11.87 & 0.006 \\
$\mathrm{X}_{3}\left(\right.$ Temperature, $\left.{ }^{\circ} \mathrm{C}\right)$ & 1 & 7.5784 & 0.3988 & 0.61 & 0.454 \\
$\mathrm{X}_{1} \mathrm{X}_{2}$ & 1 & 13.9271 & 15.6784 & 23.86 & 0.001 \\
$\mathrm{X}_{1} \mathrm{X}_{3}$ & 1 & 8.4326 & 8.3531 & 12.71 & 0.005 \\
$\mathrm{X}_{2} \mathrm{X}_{3}$ & 1 & 0.0000 & 0.0000 & 0.00 & 0.996 \\
$\mathrm{X}_{1}{ }^{2}$ & 1 & 4.4342 & 4.4342 & 6.75 & 0.027 \\
$\mathrm{X}_{2}{ }^{2}$ & 1 & 0.5157 & 0.5157 & 0.78 & 0.396 \\
$\mathrm{X}_{3}{ }^{2}$ & 1 & 0.0226 & 0.0226 & 0.03 & 0.857 \\
Lack of fit & 5 & 2.4163 & 0.4833 & 0.58 & 0.717 \\
\hline Caffeine content & & & & & \\
\hline Model & 9 & 7.5879 & 0.8431 & 11.24 & 0.000 \\
$\mathrm{X}_{1}($ Ethanol\%, v/v) & 1 & 2.8716 & 2.2364 & 29.82 & 0.000 \\
$\mathrm{X}_{2}($ Time, min) & 1 & 0.3873 & 0.1404 & 1.87 & 0.201 \\
$\mathrm{X}_{3}\left(\right.$ Temperature, $\left.{ }^{\circ} \mathrm{C}\right)$ & 1 & 1.1878 & 0.0633 & 0.84 & 0.380 \\
$\mathrm{X}_{1} \mathrm{X}_{2}$ & 1 & 2.3152 & 2.2194 & 29.60 & 0.000 \\
$\mathrm{X}_{1} \mathrm{X}_{3}$ & 1 & 0.2536 & 0.1920 & 2.56 & 0.141 \\
$\mathrm{X}_{2} \mathrm{X}_{3}$ & 1 & 0.4088 & 0.4088 & 5.45 & 0.042 \\
$\mathrm{X}_{1}{ }^{2}$ & 1 & 0.0162 & 0.0162 & 0.22 & 0.652 \\
$\mathrm{X}_{2}{ }^{2}$ & 1 & 0.1032 & 0.1032 & 1.38 & 0.268 \\
$\mathrm{X}_{3}{ }^{2}$ & 5 & 0.0442 & 0.0442 & 0.59 & 0.460 \\
Lack of fit & 0.3907 & 0.0781 & 1.09 & 0.464 \\
\hline & & & & &
\end{tabular}

Figure $2 \mathrm{~A}$ shows the effect of the interaction of ethanol concentration and extraction time on the caffeine contents at a fixed extraction temperature of 0 level. Minimum caffeine value was obtained at the lowest ethanol concentration and reached the maximum value at $70 \%$ of ethanol concentration in the fixed extraction time of $60 \mathrm{~min}$. Figure 2B shows the effect of the interaction of ethanol concentration and extraction temperature on the caffeine contents at a fixed extraction time of 0 level. Minimum caffeine value was also obtained at the lowest ethanol concentration and reached the maximum value at $78 \%$ of ethanol concentration in the fixed extraction temperature of $40{ }^{\circ} \mathrm{C}$. Figure $2 \mathrm{C}$ shows the effect of the interaction of extraction time and extraction temperature on the caffeine contents at a fixed ethanol concentration of 0 level. Minimum caffeine value was obtained at the lowest extraction time and reached the maximum value at $79 \mathrm{~min}$ of extraction time in the fixed extraction temperature of $40{ }^{\circ} \mathrm{C}$. Moreover, we have found that ethanol concentration $\left(\mathrm{X}_{1}\right)$ was the most significant factor affecting the responses at the level of $p<0.01$. 
Figure 1. Response surface plots for the effects of ethanol concentration, extraction time and temperature on antioxidant activity of green tea extracts. (A) Ethanol concentration and extraction time; (B) ethanol concentration and extraction temperature; $(\mathbf{C})$ extraction time and temperature.

(A)

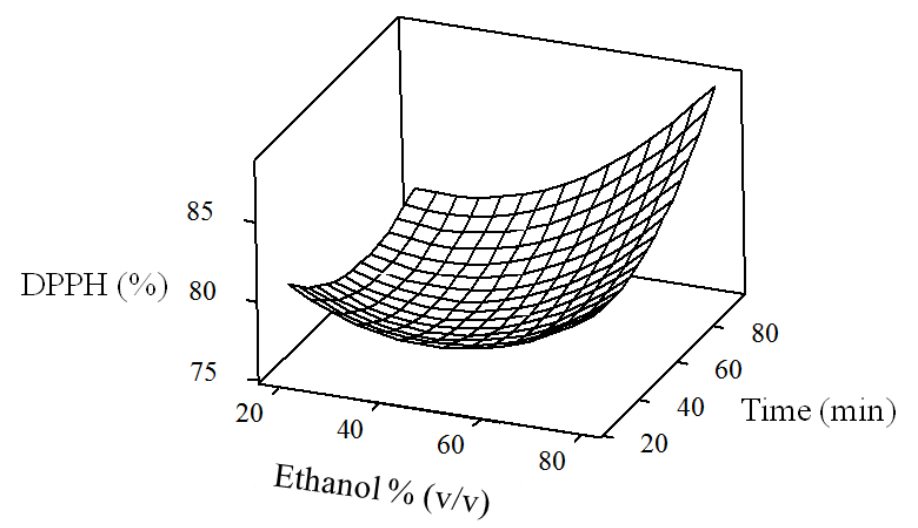

(B)

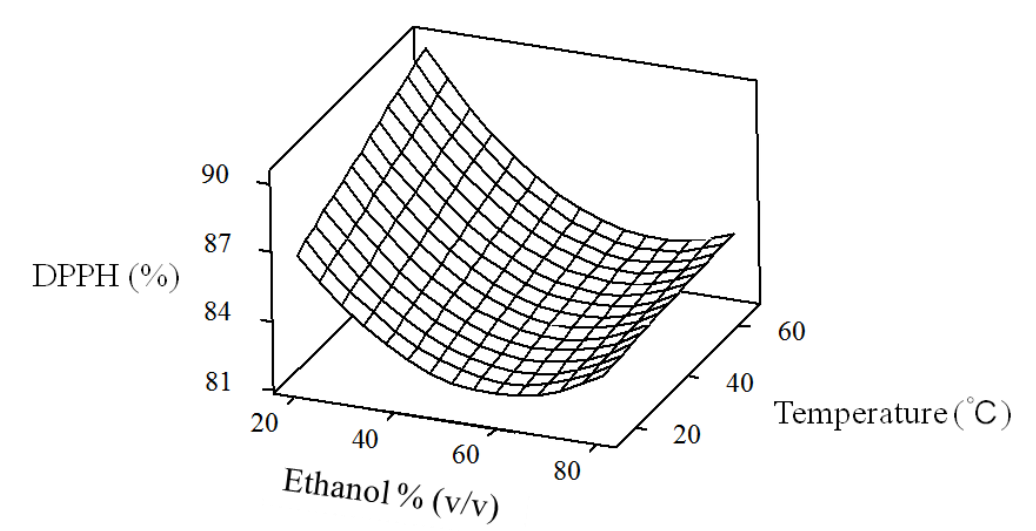

(C)

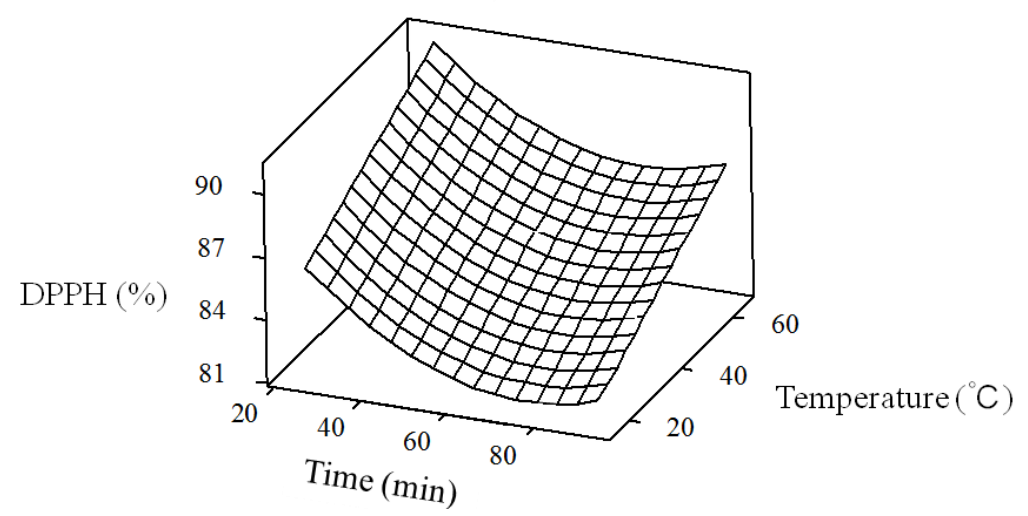

\subsection{Optimization and Verification of the Model for Ultrasonic Extraction}

Optimum process parameters achieved by maximizing antioxidant activity and simultaneously minimizing caffeine contents. During the optimization stage, the desirability function of the MINITAB (Minitab Inc., State College, PA, USA) statistical software is used to obtain the best compromise of the two responses with the weights of all 1.0. As shown in Table 4, the predicted optimal conditions for ultrasonic extraction were found at $19.7 \%$ ethanol, $26.4 \mathrm{~min}$ extraction time and $24.0{ }^{\circ} \mathrm{C}$ extraction temperature. In the predicted optimal conditions, the experimental yield of antioxidant activity and caffeine were $82.1 \%$ and $15.4 \mathrm{mg} / \mathrm{g}$, respectively. 
Figure 2. Response surface plots for the effects of ethanol concentration, extraction time and temperature on caffeine contents of green tea extracts. (A) Ethanol concentration and extraction time; $(\mathbf{B})$ ethanol concentration and extraction temperature; and $(\mathbf{C})$ extraction time and temperature.

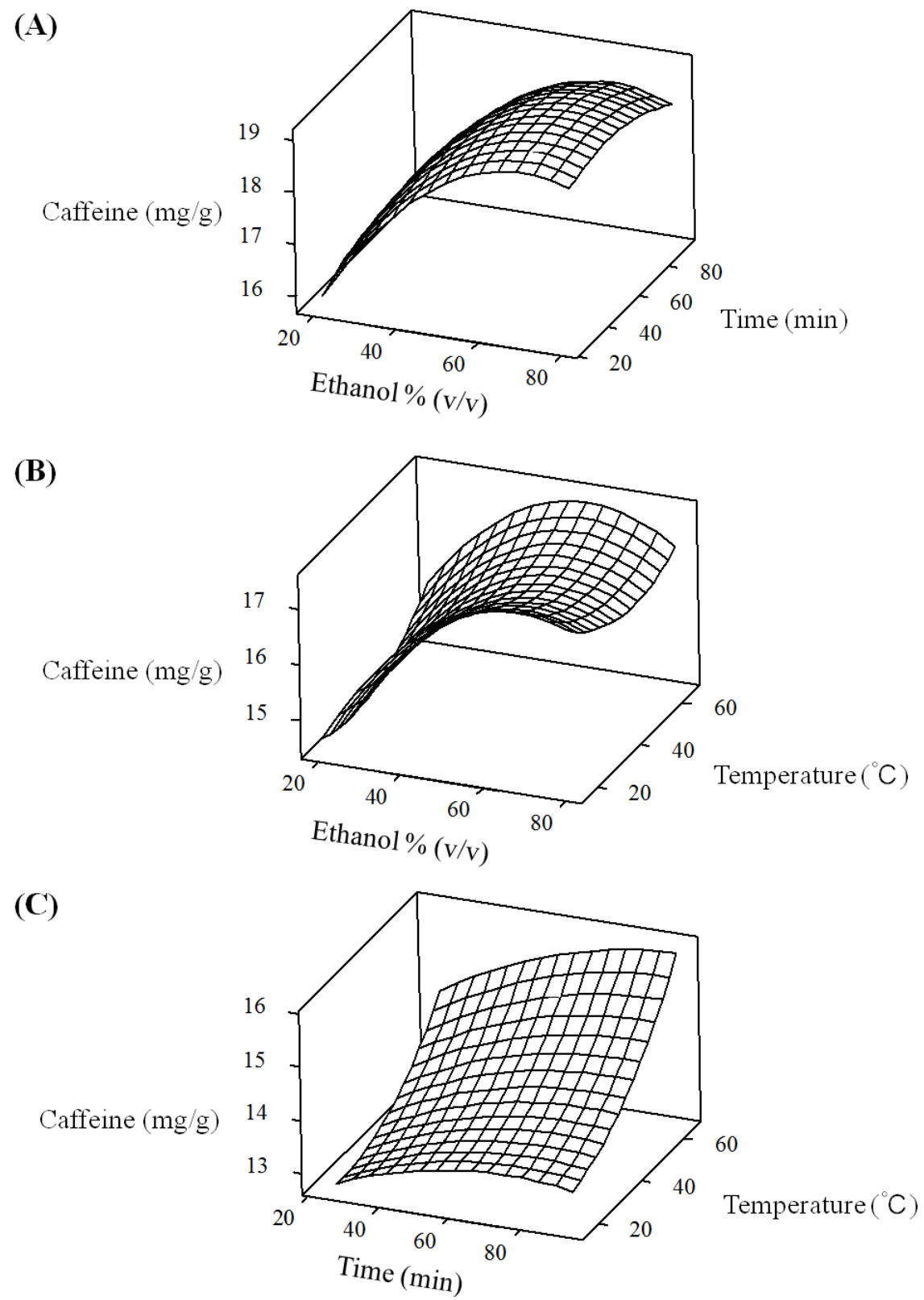

Table 4. Optimum conditions and the predicted and experimental value of responses at the optimum conditions.

\begin{tabular}{ccc}
\hline Variables & Optimum conditions (predicted) & Modified conditions (actual) \\
\hline Ethanol $(\%)$ & 19.7 & 20.0 \\
Extraction time $(\mathrm{min})$ & 26.4 & 26.0 \\
Temperature $\left({ }^{\circ} \mathrm{C}\right)$ & 24.0 & 24.0 \\
Antioxidant activity $(\%)$ & 82.1 & $82.7 \pm 0.47$ \\
Caffeine $(\mathrm{mg} / \mathrm{g})$ & 15.4 & $15.7 \pm 0.56$ \\
\hline
\end{tabular}


In order to verify the accuracy of the model for predicting maximal yield, we performed actual experiments using the optimized extraction conditions. The experimental values were very close to the predicted ones. This indicated that the optimization achieved in the present study was reliable. Horžić et al. reported that the best extraction performance of polyphenols and methylxanthines from yellow tea was achieved with the use of an ultrasound probe, especially in combination with $75 \%$ aqueous ethanol as an extraction medium [30]. This disagreement could be due to a difference in cultivar and/or target compounds in the extracts. In general, effective separation of antioxidants from a complex plant matrix is a difficult procedure due to degradation of antioxidants and co-extraction of other various compounds, which are undesirable in the antioxidant extract. High extraction temperatures can increase the yield of tea catechins because the cell walls of the green tea leaves become more permeable to the solvent and to the constituents [31,32]. However, the catechins can also be subject to degradation and epimerization when the extraction is conducted at too high temperatures [14]. This epimerization is undesirable because a large amount of the most important catechin, EGCg, is transformed into GCg [33]. Conversely, extraction at low temperatures is desirable to avoid these changes, while the efficiency of the extraction is low. Thus, it was necessary to add some organic solvent to the water to improve the efficiency of extraction of catechins from green tea. The most widely used solvents for extracting phenolic compounds are methanol, ethanol, acetone, and their water mixtures [34-38]. Especially, ethanol and water mixtures are commonly used for the extraction of phenols from plant materials. This is due to the wide range of phenols that the aqueous ethanol mixtures can dissolve and ethanol mixtures are acceptable for human consumption models [38].

\subsection{Comparison with Conventional Extraction}

In order to compare extraction efficiency, ultrasonic extraction was performed with the optimum conditions by RSM and conventional shaking extraction was carried out according to modified conditions reported by some of the previous and preliminary studies. Different reports are found in the literature. Gramza et al. reported that the antioxidant activity of green tea extracts was higher in $95 \%$ ethanol extracts than that of hot water extracts [39]. Grujic et al. reported that the antioxidant activity of Mate tea extracts was higher in $40 \%$ ethanol extracts than that of $50 \%$ and $60 \%$ ethanol concentration, respectively [40]. Mohammedi et al. reported that the antioxidant activity of Tamarix aphylla leaves extracts was higher in $70 \%$ ethanol extracts than that of water extracts [41]. Chew et al. reported that the antioxidant activity of Centella asiatica tea extracts was higher in $60 \%$ ethanol extracts than that of other concentrations of ethanol [42]. Xu et al. reported that the optimal conditions for phenolic antioxidants with shaking extraction from tea fruit peel were $43 \%$ ethanol, $33 \mathrm{~min}$ extraction time and $60{ }^{\circ} \mathrm{C}$ extraction temperature [43]. In preliminary study, we found that the high content of phenolic compounds ranged from $50 \%$ to $80 \%$ ethanol concentration in the green tea (data not shown). This disagreement could be connected with a polarity of extracts.

In general, solvents extract those phytochemicals which have similar polarity as the solvents. Although the relationship between the molecular structure and their antioxidant activity were not investigated in this study, the literature suggests that the antioxidant activity of plant extracts is strongly dependent on the solvent due to the different antioxidant potentials of compounds with different polarity. Also, it should be taken into consideration that a higher ethanol to water ratio had a 
positive influence on the antioxidant activity. Thus, we determined with $70 \%$ ethanol, 120 min extraction time and $30{ }^{\circ} \mathrm{C}$ extraction temperature the reference method in comparison to the ultrasonic extraction.

The ethanol concentration and extraction time used for antioxidant extraction were significantly reduced by $72 \%$ and $78 \%$ respectively, compared to the conventional extraction. The contents of caffeine were also lowered $30 \%$ compared to the conventional extraction. However, antioxidant activity was not found to be significantly different in the different extraction methods. These results could be very useful when attempting to reduce the caffeine content in green tea. This result was supported by the Saito et al., who studied a comparison of EGCG/caffeine ratios according to the extraction system used on Brazilian green tea [44]. It is described that EGCG/Caffeine level was higher in ultrasound-assisted extraction by immersed ultrasonic bath than that in water extraction by heated magnetic stirrer. Tang also reported that ultrasonic-enhanced supercritical fluid extraction was effective at removing caffeine from green tea without damaging the structure of its active components [45]. However, this technique has some defects such as long extraction time $(4 \mathrm{~h})$ and high extraction pressure (30 MPa), resulting in high operating costs and limiting its large-scale industrial application.

Therefore, ultrasonic extraction is a promising extraction technique for antioxidants with relatively lower level caffeine from green tea, which significantly reduced the solvent usage and extraction time compared to conventional shaking extraction.

\subsection{Correlations between Antioxidant Activity and Catechins Composition}

Green tea contains various classes of polyphenols, and up to $90 \%$ of these polyphenols is composed of catechins. To determine the most important factors affecting the antioxidant activity, Pearson's correlation coefficients were calculated using the experimental RSM data. Antioxidant activity and related compounds including total polyphenol, total catechins, gallated catechins, and ratio of $\mathrm{EGCg}+\mathrm{ECg} / \mathrm{EGC}$ were used as factors (Table 5). Correlations between factor values and the antioxidant activity obtained from RSM are shown in Table 6. In the present study, the ratio of $\mathrm{EGCg}+\mathrm{ECg} / \mathrm{EGC}$ values had the highest correlations to antioxidant activity $(\mathrm{r}=0.491, p=0.028)$. The ratio of $\mathrm{EGCg}+\mathrm{ECg} / \mathrm{EGC}$ was worth considering since the three catechins, EGCg, $\mathrm{ECg}$, and EGC, represent about $80 \%$ of the total catechins in green tea. In general, EGCg and ECg are usually accepted as quality indicators of antioxidant activity in tea products [14]. This result supports that antioxidant activity relates not only to the amounts of antioxidants but also to the properties of antioxidants such as chemical structure and interactions among each other [46]. Generally, the antioxidant capacity has often been correlated with the phenolic content [47-49]. However, some authors have reported that the antioxidant activity was not correlated with the phenolic content [50,51]. This disagreement suggested that antioxidant activity was strongly dependent on the solvent due to the different antioxidant potentials of compounds with different polarity [52,53]. 
Table 5. Response values-related antioxidants obtained from experimental design.

\begin{tabular}{ccccc}
\hline Run No. & Total polyphenol & Total catechins & Gallated catechins & (EGCg + ECg)/EGC \\
\hline 1 & 167.06 & 123.36 & 57.51 & 1.22 \\
2 & 160.70 & 115.09 & 51.92 & 1.15 \\
3 & 141.43 & 91.33 & 34.61 & 0.85 \\
4 & 153.94 & 122.14 & 60.13 & 1.36 \\
5 & 157.79 & 112.13 & 50.73 & 1.15 \\
6 & 155.70 & 112.96 & 50.97 & 1.15 \\
7 & 150.62 & 112.60 & 51.24 & 1.17 \\
8 & 154.61 & 113.20 & 51.43 & 1.16 \\
9 & 142.71 & 92.37 & 34.29 & 0.83 \\
10 & 147.65 & 123.99 & 61.87 & 1.39 \\
11 & 159.89 & 112.77 & 51.35 & 1.17 \\
12 & 139.53 & 84.21 & 29.81 & 0.77 \\
13 & 153.19 & 126.29 & 63.62 & 1.42 \\
14 & 156.91 & 115.70 & 52.78 & 1.17 \\
15 & 148.48 & 104.56 & 45.05 & 1.05 \\
16 & 155.70 & 113.09 & 51.50 & 1.17 \\
17 & 144.94 & 130.66 & 68.91 & 1.57 \\
18 & 150.31 & 99.19 & 40.80 & 0.98 \\
19 & 157.45 & 134.51 & 69.23 & 1.47 \\
20 & 151.30 & 102.78 & 41.97 & 0.96 \\
\hline
\end{tabular}

Total catechins: sum of EGC, EC, GC, C, EGCg, ECg and GCg; Gallated catechins: sum of EGCg, ECg and GCg.

Table 6. Correlations between the antioxidant activity and response values obtained from the experimental design.

\begin{tabular}{ccc}
\hline Responses & Pearson's correlation coefficient & $\boldsymbol{p}$-value \\
\hline Total polyphenol & 0.015 & 0.951 \\
Total catechins & 0.461 & 0.041 \\
Gallated catechins & 0.486 & 0.030 \\
(EGCg + ECg)/EGC & 0.491 & 0.028 \\
\hline
\end{tabular}

Total catechins: sum of EGC, EC, GC, C, EGCg, ECg and GCg; Gallated catechins: sum of EGCg, ECg and GCg.

\section{Experimental}

\subsection{Tea Materials and Chemicals}

Green tea leaves (Camellia sinensis O. Kuntz) were purchased from Amorepacific Co., Ltd. (Seoul, Korea) and were pulverized to mean particle size of $20 \mu \mathrm{m}$ by jet-milling. Folin-Ciocalteu's phenol reagent, gallic acid, caffeine, (+)-catechin, (-)-epicatechin, (-)-epicatechin gallate, (+)-catechin gallate, $(-)$-epigallocatechin, $(+)$-gallocatechin, $(-)$-epigallocatechin gallate, $(+)$-gallocatechin gallate, ascorbic acid, and 2,2-diphenyl-1-picrylhydrazil (DPPH) were purchased from Sigma-Aldrich Co. All the reagents used in the HPLC analyses were of HPLC grade. 


\subsection{Ultrasonic Extraction}

The ultrasonic extraction was treated with an ultrasonic probe (SEE-SONIC II, UL-Tech. Com., Uiwang, Korea) with an ultrasonic power of 150 watts and a frequency of $20 \mathrm{kHz}$ controlled with a phase-locked loop system. The probe had a titanium horn of $2.5 \mathrm{~cm}$ in diameter and irradiated with an ultrasonic wave directly from the horn. Five $g$ of green tea powder was mixed with the appropriate solvent $(500 \mathrm{~mL})$ in the stainless steel vessel and extracted by ultrasonic probe, which was immersed in the vessel. The resulting suspensions were centrifuged at $15,000 \mathrm{~g}$ for $10 \mathrm{~min}$ and filtered by a $0.45 \mu \mathrm{m}$ syringe filter (CE Minisart RC 15, Sartorius, Goettingen, Germany) before further analysis.

\subsection{Conventional Extraction}

Shaking extraction, one of conventional extraction methods, was performed with $5 \mathrm{~g}$ green tea powder mixed with $500 \mathrm{~mL}$ of $70 \%$ ethanol concentration and extracted at $30{ }^{\circ} \mathrm{C}$ for $120 \mathrm{~min}$ in shaking incubator. The resulting suspensions were centrifuged at $15,000 \mathrm{~g}$ for $10 \mathrm{~min}$ and filtered by a $0.45 \mu \mathrm{m}$ syringe filter (CE Minisart RC 15) before further analysis.

\subsection{Experimental Design and Statistical Analysis}

Ultrasonic extraction optimized the experimental design using RSM. A Central Composite Design (CCD) consisting of twenty experimental runs was employed including six star points $(\alpha=1.682)$ points, eight factorial points and six central points. The independent variables were the ethanol concentration $\left(\mathrm{X}_{1}\right)$, extraction time $\left(\mathrm{X}_{2}\right)$, and extraction temperature $\left(\mathrm{X}_{3}\right)$ while dependent variables (response) were antioxidant activity $\left(\mathrm{Y}_{1}\right)$, and caffeine contents $\left(\mathrm{Y}_{2}\right)$. The range values of the three independent variables were determined by preliminary study. Experiments were performed in replicate and the average values were used as the response, Y. A full polynomial model was obtained with a multiple regression technique for three factors using MINITAB 16 (Minitab Inc., State College, PA, USA).

\subsection{Measurement of Antioxidant Activity}

The antioxidant activity of green tea extracts was measured using a DPPH free radical scavenging assay according to the modified method described by Yamaguchi et al. [54]. The green tea extracts $(0.5 \mathrm{~mL})$ were diluted 10 -fold with extract solvent and mixed with $0.12 \mathrm{mM}$ DPPH solution $(2.5 \mathrm{~mL})$. The mixture was vortex mixed and allowed to stand at room temperature for $30 \mathrm{~min}$. The absorbance of the resulting solution was measured at $517 \mathrm{~nm}$ and the scavenging activity of DPPH free radicals was calculated by using the following formula: scavenging activity $(\%)=100-[$ (absorbance of sample at $517 \mathrm{~nm} /$ absorbance of blank at $517 \mathrm{~nm}) \times 100$ ]. Blank is the absorbance of the control reaction which contains all of the components without the tested sample.

\subsection{Measurement of Caffeine and Catechins Contents}

The contents of caffeine and catechins in the green tea extracts were analyzed according to the modified method described by $\mathrm{Hu}$ et al. [55]. Prepared sample analyzed by HPLC (JASCO Co., Tokyo, Japan) using a XTerra RP18 column $(3.5 \mu \mathrm{m}, 4.6 \times 150 \mathrm{~mm}$, Waters, Milford, MA, USA) at 
$40{ }^{\circ} \mathrm{C}$ and multi-wavelength detector (MD-2010 Plus, JASCO Co., Tokyo, Japan) was set at $210 \mathrm{~nm}$ (Figure 3). The mobile phase was composed of two solution A ( $0.2 \%$ ortho phosphoric acid) and solution B (methanol) and eluted with a linear gradient elution of $0 \mathrm{~min}, 82 \% \mathrm{~A} ; 15 \mathrm{~min}, 40 \%$ at a flow rate of $1.0 \mathrm{~mL} / \mathrm{min}$. Individual catechins and caffeine contents were calculated by comparing with an external standard calibration curves of each analyte. All the analytes showed good linearity $\left(\mathrm{R}^{2}>0.99\right)$ in a relatively wide concentration range.

Figure 3. HPLC chromatograms of standard solution of caffeine and catechins (A) and extracts (B). GC, (+)-gallocatechin; EGC, (-)-epigallocatechin; EC, (-)-epicatechin; EGCg, (-)-epigallocatechin gallate; GCg, (+)-gallocatechin gallate; ECg, (-)-epicatechin gallate; $\mathrm{Cg},(+)$-catechin gallate.

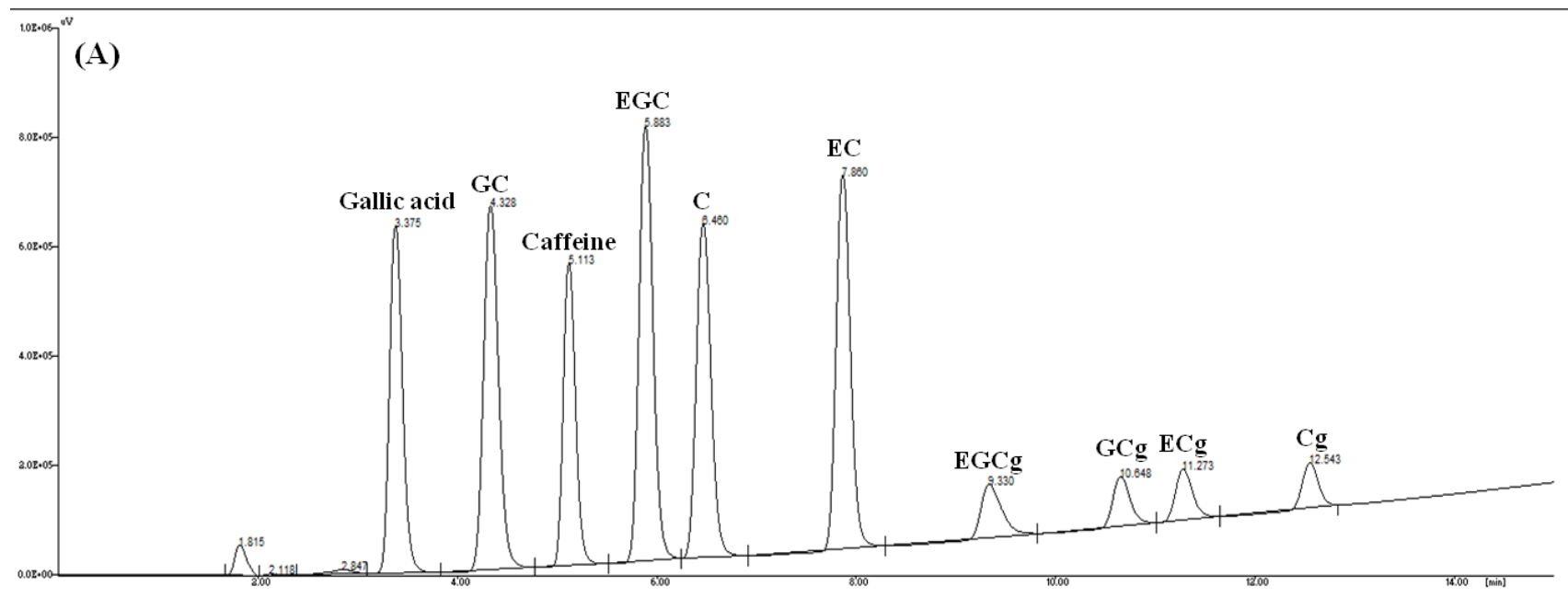

(B)

\subsection{Measurement of Total Polyphenol Contents}

The contents of total polyphenol in the green tea extracts were measured by the modified Folin-Ciocalteu assay carried out according to the method described by Singleton and Rossi [56]. The extracts $(0.1 \mathrm{~mL})$ were diluted 10-fold with extract solvent and mixed with $0.2 \mathrm{~N}$ Folin-Ciocalteu reagent $(1 \mathrm{~mL})$. The mixture was allowed to stand at room temperature for 3 min after which $1 \mathrm{~mL}$ of saturated sodium carbonate was added. The final mixture was incubated at room temperature for $60 \mathrm{~min}$ and absorbance of the resulting solution measured at $735 \mathrm{~nm}$. The contents of total polyphenol 
were calculated by comparing with an external standard calibration curve of gallic acid $\left(\mathrm{R}^{2}=0.9983\right)$ and were expressed as gallic acid equivalents (GAE, g gallic acid) per $100 \mathrm{~g}$ of sample

\section{Conclusions}

In the present study, response surface methodology was used to optimize the ultrasonic extraction of phenolic antioxidants with relatively low caffeine content from green tea. A central composite design was used to determine the optimum process parameters and the second order polynomial models for predicting responses were obtained. Ethanol concentration was the most significant factor affecting antioxidant activity and caffeine content and the optimal extraction conditions were $19.7 \%$ ethanol for $26.4 \mathrm{~min}$ at $24.0{ }^{\circ} \mathrm{C}$. Under optimized conditions the experimental values were very close to the predicted values. Compared to the conventional shaking extraction methods, ultrasonic extraction requires less extraction time, lower temperature and provides lower caffeine content without a decrease of antioxidant activity. As such, it may be said that ultrasonic extraction is an effective and practical method for obtaining phenolic antioxidants with relatively low caffeine content from green.

\section{Acknowledgments}

This work was supported by research grants from the Korea Food Research Institute.

\section{Conflicts of Interest}

The authors declare no conflict of interest.

\section{References}

1. Cabrera, C.; Artacho, R.; Giménez, R. Beneficial effects of green tea. J. Am. Coll. Nutr. 2006, 25, 79-99.

2. Khan, N.; Mukhtar, H. Tea polyphenols for health promotion. Life Sci. 2007, 81, 519-533.

3. Yamamoto, T.; Juneja, L.R.; Chu, D.; Kim, M. Chemistry and Applications of Green Tea; CRC Press: Boca Raton, FL, USA, 1997; pp. 26-33.

4. Hara, Y. Green Tea: Health Benefits and Applications; Marcel Dekker Inc.: New York, NY, USA, 2001; pp. 183-219.

5. Bozkurt, H. Utilization of natural antioxidants: Green tea extract and thymbra spicata oil in Turkish dry-fermented sausage. Meat Sci. 2006, 73, 442-450.

6. Nehlig, A.; Daval, J.L.; Debry, G. Caffeine and the central nervous system: Mechanisms of action, biochemical, metabolic and psychostimulant effects. Brain Res. Rev. 1992, 17, 139-170.

7. Snel, J.; Lorist, M.M. Effects of caffeine on sleep and cognition. Prog. Brain Res. 2011, 190, 105-117.

8. Uzunalic, A.P.; Skerget, M.; Knez, Z.; Weinreich, B.; Otto, F.; Gruner, S. Extraction of active ingredients from green tea (Camellia sinensis): Extraction efficiency of major catechins and caffeine. Food Chem. 2006, 96, 597-605.

9. Row, K.H.; Jin, Y. Recovery of catechin compounds from Korean tea by solvent extraction. Bioresour. Technol. 2006, 97, 790-793. 
10. Shi, J.; Nawaz, H.; Pohorly, J.; Mittal, G.; Kakuda, Y.; Jiang, Y. Extraction of polyphenolics from plant material for functional foods-engineering and technology. Food Rev. Int. 2005, 21, 139-166.

11. Nwuha, V.; Nakajima, M.; Tong, J.; Ichikawa, S. Solubility of green tea extracts in pure solvents and edible oils. J. Food Eng. 1999, 40, 161-165.

12. Wang, H.; Keith, H. Epimerization of catechins in green tea infusions. Food Chem. 2000, 70, 337-344.

13. Palma, M.; Pineiro, Z.; Barroso, C.G. Stability of phenolic compounds during extraction with superheated solvents. J. Chromatogr. A 2001, 921, 169-174.

14. Chen, Z.Y.; Zhu, Q.Y.; Tsang, D.; Huang, Y. Degradation of green tea catechins in tea drinks. J. Agric. Food Chem. 2001, 49, 477-482.

15. Mohamed, R.S.; Saldana, M.D.A.; Mazzafera, P.; Zetzl, C.; Brunner, G. Extraction of caffeine, theobromine, and cocoa butter from Brazilian cocoa beans using supercritical $\mathrm{CO}_{2}$ and ethan. Ind. Eng. Chem. Res. 2002, 41, 6751-6758.

16. Park, H.S.; Choi, H.K.; Lee, S.J.; Park, K.W.; Choi, S.G.; Kim, K.H. Effect of mass transfer on the removal of caffeine from green tea by supercritical carbon dioxide. J. Supercrit. Fluid. 2007, 42, 205-211.

17. Nkhili, E.; Valerie, T.; El Hajji, H.; El Boustani, E.S.; Chemat, F.; Dangles, O. Microwaveassisted water extraction of green tea polyphenols. Phytochem. Anal. 2009, 20, 408-415.

18. Wang, L.; Qin, P.; Hu, Y. Study on the microwave-assisted extraction of polyphenols from tea. Front. Chem. Eng. Chin. 2010, 4, 307-313.

19. Mason, T.J.; Paniwnyk, L.; Lorimer, J.P. The uses of ultrasound in food technology. Ultrason. Sonochem. 1996, 3, S253-S260.

20. Albu, S.; Joyce, E.; Paniwnyk, L.; Lorimer, J.P.; Mason, T.J. Potential for the use of ultrasound in the extraction of antioxidants from Rosmarinus officinalis for the food and pharmaceutical industry. Ultrason. Sonochem. 2004, 11, 261-265.

21. Yang, Y.; Zhang, F. Ultrasound-assisted extraction of rutin and quercetin from Euonymus alatus (Thunb.) Sieb. Ultrason. Sonochem. 2008, 15, 308-313.

22. Rostagno, M.A.; Palma, M.; Barroso, C.G. Ultrasound-assisted extraction of soy isoflavones. J. Chromatogr. A 2003, 1012, 119-128.

23. Pinelo, M.; Rubilar, M.; Jerez, M.; Sineiro, J.; Nunez, M.J. Effect of solvent, temperature and solvent-to-solid ratio on the total phenolic content and antiradical activity of extracts from different components of grape pomace. J. Agric. Food Chem. 2005, 53, 2111-2117.

24. Tan, P.W.; Tan, C.P.; Ho, C.W. Antioxidant properties: Effects of solid-to-solvent ratio on antioxidant compounds and capacities of Pegaga (Centella asiatica). Int. Food Res. 2011, 18, $557-562$.

25. Hajj, Y.E.; Louka, N.; Nguyen, C.; Maroun, R.G. Low cost process for phenolic compounds extraction from cabernet sauvignon grapes (Vitis vinifera L. cv. cabernet sauvignon). Optimization by response surface methodology. Food Nutr. Sci. 2012, 3, 89-103.

26. Zhao, L.C.; Liang, J.; Li, W.; Cheng, K.M.; Xia, X.; Deng, X.; Yang, G.L. The use of response surface methodology to optimize the ultrasound-assisted extraction of five anthraquinones from Rheum palmatum L. Molecules 2011, 16, 5928-5937. 
27. Liyana-Pathirana, C.; Shahidi, F. Optimization of extraction of phenolic compounds from wheat using response surface methodology. Food Chem. 2005, 93, 47-56.

28. Ondrejovič, M.; Kraic, F.; Benkovičová, H.; Šilhár, S. Optimisation of antioxidant extraction from lemon balm (Melissa officinalis). Czech J. Food Sci. 2012, 30, 385-393.

29. Trinh, T.K.; Kang, L.S. Application of response surface method as an experimental design to optimize coagulation test. Environ. Eng. Res. 2010, 15, 63-70.

30. Horžić, D.; Jambrak, A.R.; Belščak-Cvitanović, A.; Komes, D.; Lelas, V. Comparison of conventional and ultrasound assisted extraction techniques of yellow tea and bioactive composition of obtained extracts. Food Bioprocess Technol. 2012, 5, 2858-2870.

31. Vuong, Q.V.; Golding, J.B.; Nguyen, M.; Roach, P.D. Extraction and isolation of catechins from tea. J. Sep. Sci. 2010, 33, 3415-3428.

32. Vuong, Q.V.; Stathopoulos, C.E.; Nguyen, M.H.; Golding, J.B.; Roach, P.D. Isolation of green tea catechins and their utilization in the food industry. Food Rev. Int. 2011, 27, 227-247.

33. Lin, Y.; Tsai, Y.; Tsai, J.; Lin, J. Factors affecting the levels of tea polyphenols and caffeine in tea leaves. J. Agric. Food. Chem. 2003, 51, 1864-1873.

34. Michiels, J.A.; Kevers, C.; Pincemail, J.; Defraigne, J.O.; Dommes, J. Extraction conditions can greatly influence antioxidant capacity assays in plant food matrices. Food Chem. 2012, 130, 986-993.

35. Tomsone, L.; Kruma, Z.; Galoburda, R. Comparison of Different Solvents and Extraction Methods for Isolation of Phenolic Compounds from Horseradish Roots (Armoracia Rusticana). In Proceedings of World Academy of Science, Engineering and Technology (No. 64), World Academy of Science, Engineering and Technology, Paris, France, 25 April 2012.

36. Pinelo, M.; Rubilar, M.; Sineiro, J.; Nunez, M.J. Extraction of antioxidant phenolics from almond hulls (Prunes amygdalus) and pine sawdust (Pines pinaster). Food Chem. 2004, 85, 267-273.

37. Durling, N.E.; Catchpole, O.J.; Grey, J.B.; Webby, R.F.; Mitchell, K.A.; Foo, L.Y.; Perry, N.B. Extraction of phenolics and essential oil from dried sage (Salvia officinalis) using ethanol-water mixtures. Food Chem. 2007, 101, 1417-1424.

38. Alothman, M.; Rajeev, B.; Karim, A.A. Antioxidant capacity and phenolic content of selected tropical fruits from Malaysia, extracted with different solvents. Food Chem. 2009, 115, 785-788.

39. Gramza, A.; Pawlak-Lemanska, K.; Korczak, J.; Wasowicz, E.; Rudzinska, M. Tea extracts as free radical scavengers. Pol. J. Environ. Stud. 2005, 14, 861-867.

40. Grujic, N.; Lepojevic, Z.; Srdjenovic, B.; Vladic, J.; Sudji, J. Effects of different extraction methods and conditions on the phenolic composition of mate tea extracts. Molecules 2012, 17, 2518-2528.

41. Mohammedi, Z.; Atik, F. Impact of solvent extraction type on total polyphenols content and biological activity from Tamarix Aphylla (L.) karst. Int. J. Pharma Bio Sci. 2011, 2, 609-615.

42. Chew, K.K.; Ng, S.Y.; Thoo, Y.Y.; Khoo, M.Z.; Wan Aida, W.M.; Ho, C.W. Effect of ethanol concentration, extraction time and extraction temperature on the recovery of phenolic compounds and antioxidant capacity of Centella asiatica extracts. Int. Food Res. J. 2011, 18, 571-578.

43. Xu, P.; Bao, J.; Gao, J.; Zhou, T.; Wang, Y. Optimization of extraction of phenolic antioxidants from tea (Camellia sinesis L.) fruit peel biomass using response surface methodology. Bioresources 2012, 7, 2431-2443. 
44. Saito, S.T.; Gosmann, G.; Saffi, J.; Presser, M.; Richter, M.F.; Bergold, A.M. Characterization of the constituents and antioxidant activity of Brazilian green tea (Camellia sinensis var. assamica IAC-259 cultivar) extracts. J. Agric. Food Chem. 2007, 55, 9409-9414.

45. Tang, W.Q.; Li, D.C.; Lv, Y.X.; Jiang, J.G. Extraction and removal of caffeine from green tea by ultrasonic-enhanced supercritical fluid. J. Food Sci. 2010, 75, C363-C368.

46. Blokhina, O.; Virolainen, E.; Fagerstedt, K.V. Antioxidant, oxidative damage and oxygen deprivation stress: A Review. Ann. Bot. Lond. 2003, 91, 179-194.

47. Li, X.; Wu, X.; Huang L. Correlation between antioxidant activities and phenolic contents of radix Angelicae sinensis (Danggui). Molecules 2009, 14, 5349-5361.

48. Tosun, M.; Ercisli, S.; Sengul, M.; Ozer, H.; Polat, T.; Ozturk, E. Antioxidant properties and total phenolic content of eight salvia species from Turkey. Biol. Res. 2009, 42, 175-181.

49. Zahin, M.; Aqil, F.; Ahmad, I. The in vitro antioxidant activity and total phenolic content of four Indian medicinal plants. Int. J. Pharm. Pharm. Sci. 2009, 1, 88-95.

50. Bajpai, M.; Pande, A.; Tewari, S.K.; Prakash, D. Phenolic contents and antioxidant activity of some food and medicinal plants. Int. J. Food Sci. Nutr. 2005, 56, 287-291.

51. Ruanma, K.; Shank, L.; Chairote, G. Phenolic content and antioxidant properties of green chilli paste and its ingredients. Maejo Int. J. Sci. Technol. 2010, 4, 193-200.

52. Julkunen-Tiito, R. Phenolic constituents in the leaves of northern willows, methods for the analysis of certain phenolics. J. Agric. Food Chem. 1985, 33, 213-217.

53. Marinova, E.M.; Yanishlieva, N. Antioxidative activity of extracts from selected species of the family Lamiaceae in sunflower oil. Food Chem. 1997, 58, 245-248.

54. Yamaguchi, T.; Takamura, H.; Matoba, T.; Terao, J. HPLC method for evaluation of the free radical-scavenging activity of foods by using 1,1,-diphenyl-2-picrylhydrazyl. Biosci. Biotechnol. Biochem. 1998, 62, 1201-1204.

55. Hu, B.; Wang, L.; Zhou, B.; Zhang, X.; Sun, Y.; Ye, H.; Zhao, L.; Hu, Q.; Wang, G.; Zeng, X. Efficient procedure for isolating methylated catechins from green tea and effective simultaneous analysis of tea catechins, three purine alkaloids, and gallic acid in tea by high-performance liquid chromatography with diode array detection. J. Chromatogr. A 2009, 1216, 3223-3231.

56. Singleton, V.L.; Rossi, J.A. Colorimetry of total phenolics with phosphomolybdic phosphotungstic acid reagents. Am. J. Enol. Vitic. 1965, 16, 144-158.

Sample Availability: Samples of the phenolic antioxidants with relatively low caffeine content are available from the authors.

(C) 2013 by the authors; licensee MDPI, Basel, Switzerland. This article is an open access article distributed under the terms and conditions of the Creative Commons Attribution license (http://creativecommons.org/licenses/by/3.0/). 